\title{
Symptom Onset
}

National Cancer Institute

\section{Source}

National Cancer Institute. Symptom Onset. NCI Thesaurus. Code C124353.

The point at which the symptoms began or were first noted. 